\title{
Video Lectures in Online Graduate Education: Relationship between Use of Lectures and Outcome Measures
}

\author{
Dana Reinecke and Lori L. Finn \\ Center for Applied Behavior Analysis, \\ The Sage Colleges, Troy, NY, USA \\ dana@room2grow.org finnl@sage.edu
}

\begin{abstract}
The present study is a post-hoc analysis of data automatically recorded by an online teaching platform in a graduate course in research methods. The course is part of a sequence that is delivered completely online in a program preparing students to become Board Certified Behavior Analysts. Data analyzed included frequency of access to video lectures and PowerPoint slides (PPTs) across each week of the course, and how access related to final grades in the course. The general conclusion was that higher grades were associated with greater frequency of access to video lectures and PPTs, although students who earned As and Bs tended to access these materials with gradually less frequency over time. Conversely, students who earned Cs or lower tended to access materials more frequently over time. Overall, students who earned As were more likely to employ a consistent pattern of access than students who earned lower grades. Limitations of the current project include a small sample size, skewed grade distribution, and a post hoc analysis of data instead of an experimental manipulation. Suggestions for future research are discussed.
\end{abstract}

Keywords: online class, video lecture, PowerPoint, student outcomes, student choice

\section{Introduction}

Online learning is a rapidly growing industry (Means, Toyama, Murphy, Bakia, \& Jones, 2009), bringing learning opportunities to many who might not otherwise be able to access an education. Convenience and flexibility are key benefits of online learning (Marks, Sibley, \& Arbaugh, 2005). Online learning also eliminates physical barriers to education, such as geographic distance (Hines \& Pearl, 2004).

The effectiveness of online education has been demonstrated across thousands of studies. Means et al. (2009) conducted a meta-analysis that found that students learning online had better outcomes than those learning in traditional settings.

Material published as part of this publication, either on-line or in print, is copyrighted by the Informing Science Institute. Permission to make digital or paper copy of part or all of these works for personal or classroom use is granted without fee provided that the copies are not made or distributed for profit or commercial advantage AND that copies 1) bear this notice in full and 2) give the full citation on the first page. It is permissible to abstract these works so long as credit is given. To copy in all other cases or to republish or to post on a server or to redistribute to lists requires specific permission and payment of a fee. Contact Publisher@InformingScience.org to request redistribution permission.
Online education easily lends itself to delivery of content in multiple formats. Instructors may direct students towards publicly available materials, such as YouTube videos and blogs, or towards copyrighted materials, such as texts and articles available for purchase or through digital libraries. Instructors may also create and distribute original material, including written content, PowerPoints and other visual presentations, and video lectures. 
Cifuentes and Lents (2009) describe benefits of video lectures. Unlike traditional, live lectures, students can pause video lectures to take notes, thus allowing them to maintain complete attention to the speaker. The ability to pause video lectures can also be helpful when a student finds a concept difficult or confusing, as it allows the student to look at other sources. Finally, video lectures are usually continuously available and available for multiple viewings. Traditional lectures might be taped by a student for later review, with the instructor's permission, but are usually not designed to be viewed or listened to multiple times or in small chunks. Online materials that included video lectures and interactive links were presented to business students in a study by Batinic, Gruber, and Jading (2009). Students who focused on lecture content, watched with few interruptions, and repeated the lectures were found to score better on tests than students who did not attend closely to the lectures and who interacted more with links. This suggests that video lectures may improve student outcomes.

Video lectures have been found to be effective across a variety of online learning environments. For example, in a 10-year study of telemedicine in Taiwan, Wang (2008) found that quantity and quality of health care services improved with continuing education lectures delivered online. In another study of 34 students taking an on-campus course, students who chose to use available video lectures scored higher on quizzes than those who did not use video lectures (Latchman \& Latchman, 2001). Research conducted with accounting students found that those who did not have access to video lectures failed their course at a higher rate than those who did have video lectures available to them. For these students, final exam scores were improved across all grade ranges in the group who had access to video lectures (Brecht \& Ogilby, 2008). Similarly, in another study biology students were provided with either live or video lectures. Although students scored equally well on exams under both conditions, those who had access to video lectures had improved scores when they viewed the lectures versus when they did not (Cifuentes \& Lents, 2009).

Although these studies demonstrate that video lectures can be beneficial to students and improve test scores and course grades, research also shows that students do not consistently avail themselves of this technology. This is not surprising in light of a finding by Hung and Zhang (2008) that online learners do not consistently access passive course materials in general. Cifuentes and Lents (2009) found that not all students watched lectures at first, although use of video lectures increased over time. Similarly, medical students who were given access to video lectures as supplementary materials were found to view them very infrequently (Chandrasekhar, Espiritu, Gruener, Hoyt, McNulty, \& Naheedy, 2009). In this analysis, students mostly used video lectures to help with difficult concepts. In Latchman and Latchman's analysis (2001), video lectures were made available to 34 students, but only 21 of them chose to use the lectures. Student preference for and use of video lectures should be thoroughly analyzed to determine how best to use lectures to improve student outcomes.

The current research question examines the use of video lectures by graduate students in a fully online program. Online activity logs allow for a post hoc analysis of preference for video lectures. The relationship between lecture use and course outcomes is analyzed and discussed in the context of students' selection of effective strategies for learning, and their consistency in choosing these strategies.

\section{Method}

\section{Participants}

This analysis includes data from 124 graduate students across three semesters. Graduate students were enrolled in one of the two programs of the Center for Applied Behavior Analysis (CABA) at The Sage Colleges. Both programs are delivered entirely online, and both programs provide a coursework sequence approved by the Behavior Analyst Certification Board (BACB). One program 
delivers a Master's degree in Applied Behavior Analysis and Autism, while the other program delivers a Certificate in Applied Behavior Analysis.

Data were gathered from ABA 605: Research in ABA, a course that students typically take in the second semester of study. Data were collected across 3 semesters of study in which 11 sections of this course were offered, taught by 7 different instructors. There were 113 female participants, and 11 male participants. Most participants lived within the United States or Canada.

\section{Setting}

The online environment for ABA 605 is considered the setting for this research project. The course was delivered using the Moodle learning management system. Content and activities were arranged across 13 weekly topics. Each weekly topic contained a link to an Adobe portable document format file (PDF) of PowerPoint slides (PPT) from the weekly lecture, as well as links to the streaming videos used as lectures. Additionally, each weekly topic contained links to forum discussions, instructions and upload areas for written assignments, an upload area for answers to study questions, and a 10-question quiz.

\section{Materials}

The audio-visual lectures that were presented in each weekly topic were broken up into one to four 10-20 minute segments. Each segment was uploaded as a separate streaming video. The instructor who prepared all of the lectures also taught two of the sections of the course from which data were gathered.

Lectures were recorded using Camtasia and PowerPoint. The PowerPoint slides were prepared based upon the textbook chapter assigned for the week. The instructor provided commentary and examples to complement the textbook information. The PowerPoint slides were also saved as PDF files that students were able to view, save, download, and print as they wished. All content was available ondemand throughout the whole semester, and could be accessed as many times as students wanted.

\section{Measures/Grading}

Course grades were based upon the activities available to students each week, including forum discussions, study questions, quizzes, and written assignments. The quizzes and study questions were based directly upon the textbook and accounted for $27 \%$ of the total class grade. The remaining $73 \%$ of the class grade was based upon the discussion forums and written assignments, which reflected applications of the information from the textbook.

\section{Procedures}

Data were de-identified as per IRB protocols. A graduate assistant, who was not a student within one of the CABA programs, coded grades and preference data across all students in each section of the course across two semesters. These data were accessed using the Gradebook and Reports functions in the Moodle courses where the classes were housed.

Relevant data included final course grade, as well as number of times each participant clicked on the links to open the weekly PDF file and video lectures. These data were aggregated according to categories of class outcomes and subject to visual analysis.

\section{Results}

Data showing the grade distribution in the class are presented in Figure 1. Most of the students earned As over the three semesters that were analyzed. The course structure included multiple oppor- 
tunities to resubmit work and to retake quizzes, so most students tended to earn high grades in this course.

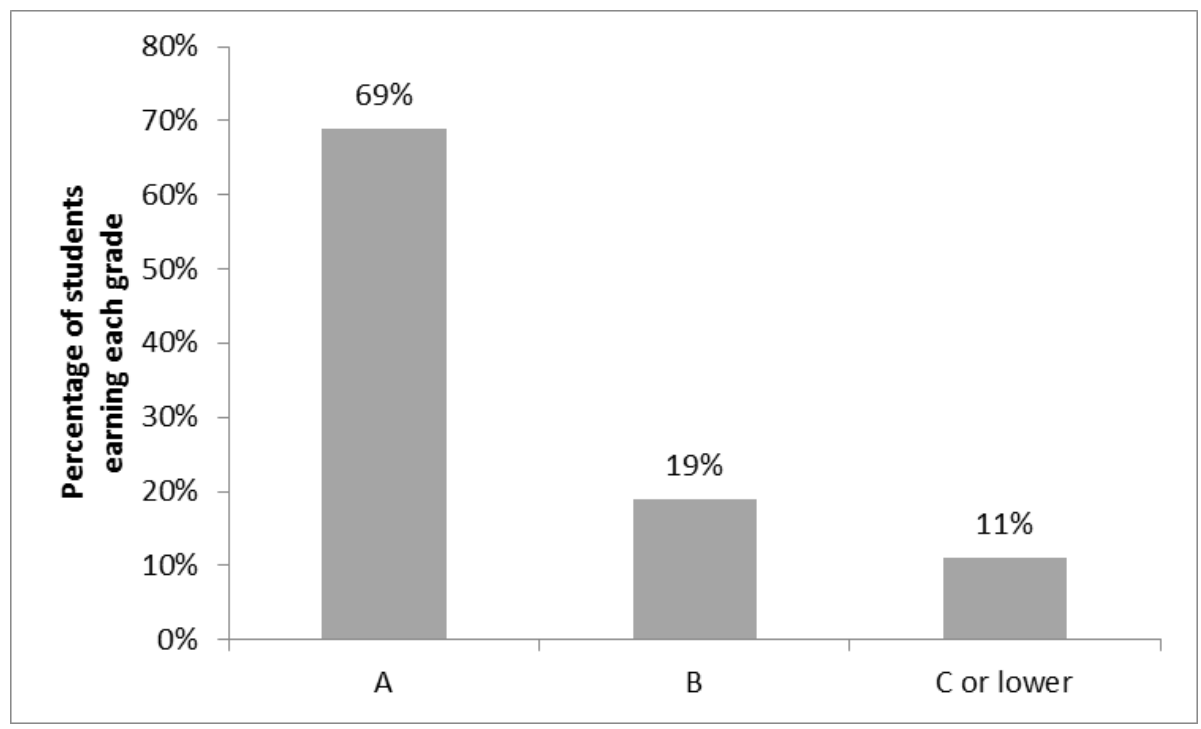

Figure 1. Distribution of grades across all students in all semesters.

Data showing number of students who accessed lectures and number of lecture views across the semester are presented in Figure 2. The greatest number of lecture views and number of students who viewed lectures occurred in the first week of class, when the lecture was viewed 143 times by 87 students. The number of views and students who viewed lectures then dropped to 95 views by 66 students in the second week, followed by a gradually decreasing trend in the number of students who viewed lectures over the rest of the semester. The number of lecture views did not decline as steadily, but ultimately lectures were viewed 50 times by 23 students in the twelfth week of class.

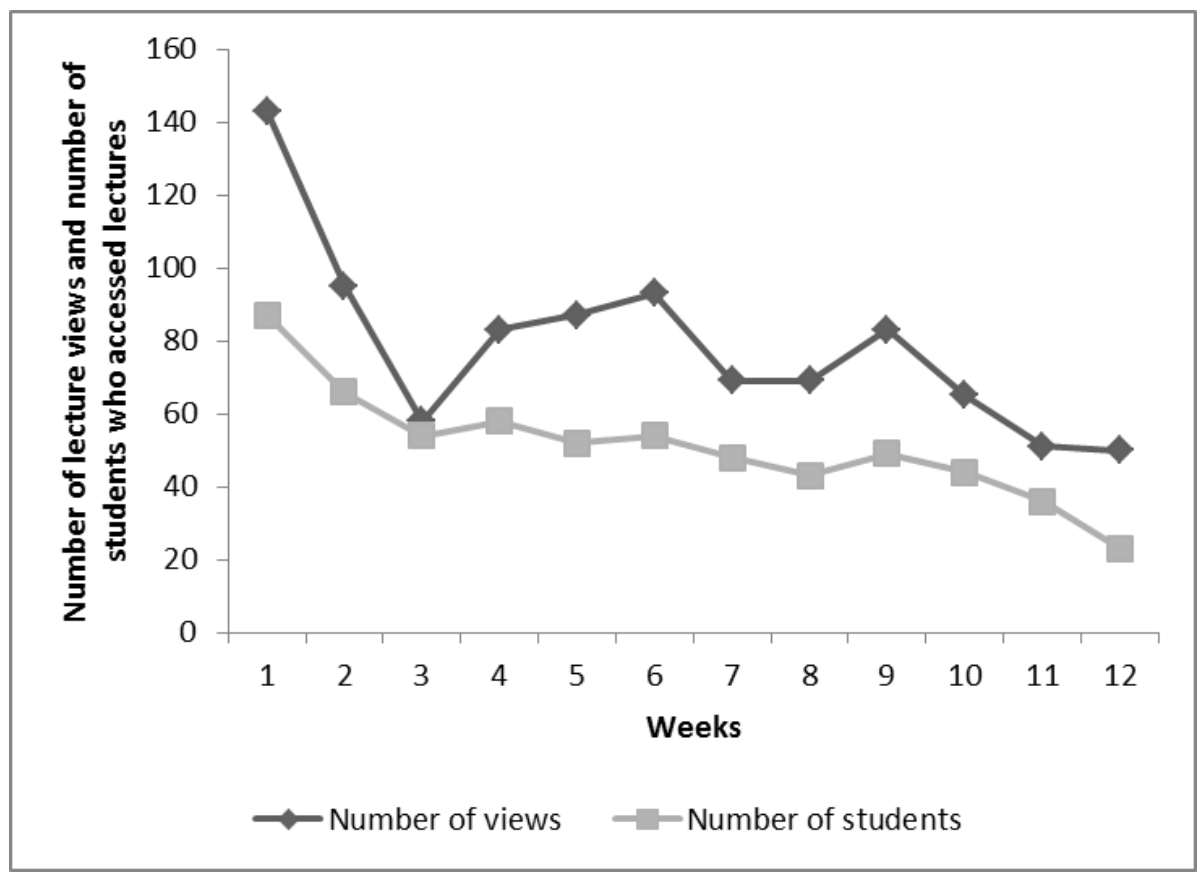

Figure 2. Number of lecture views and number of students who viewed lectures across each week of the course. 
A similar pattern is noted in Figure 3, which presents data on number of students who accessed PPTs and number of PPT views across the semester. For the first week of the semester, 76 students accessed PPTs 134 times. The decline in number of PPT views and students viewing PPTs was slower than the decline in lecture views over the rest of the semester, with 42 students viewing the PPT 57 times in the twelfth week of class.

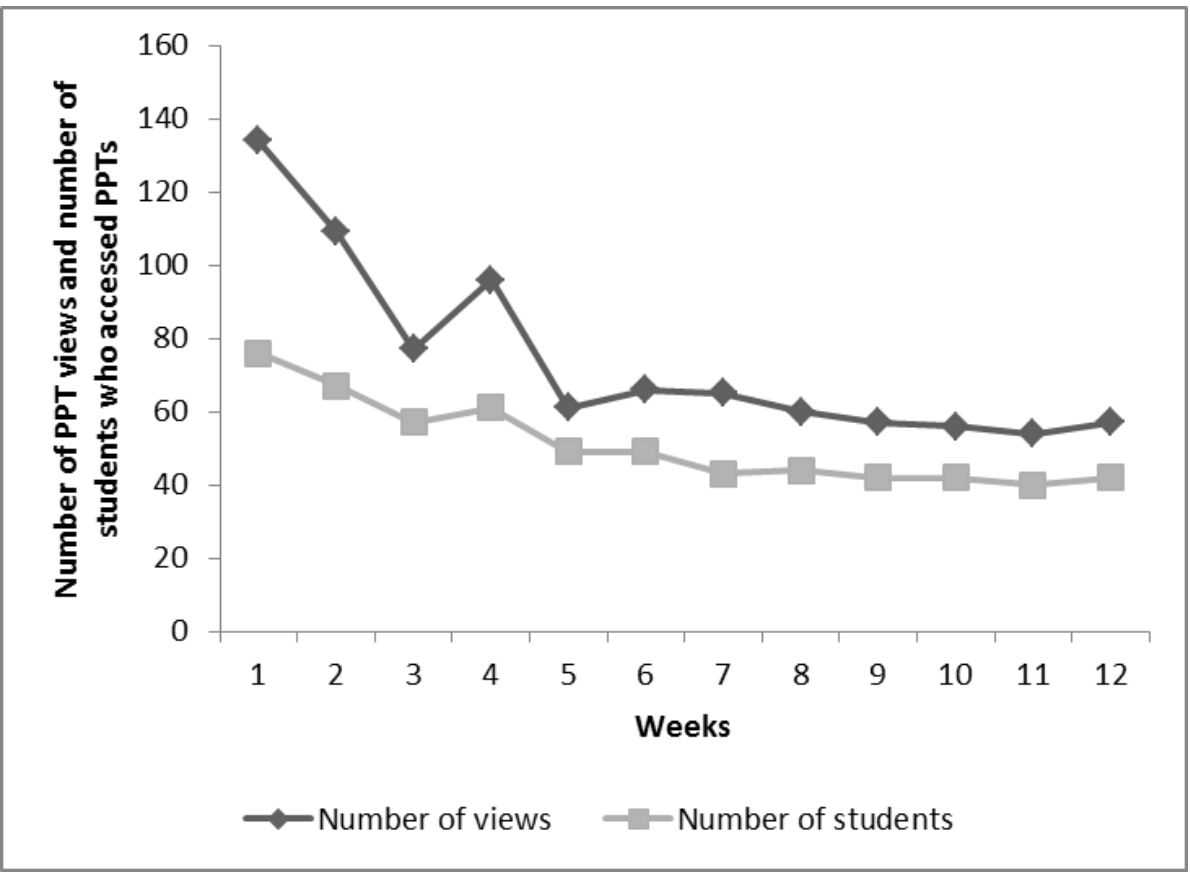

Figure 3. Number of PPT views and number of students who viewed PPTs across each week of the course.

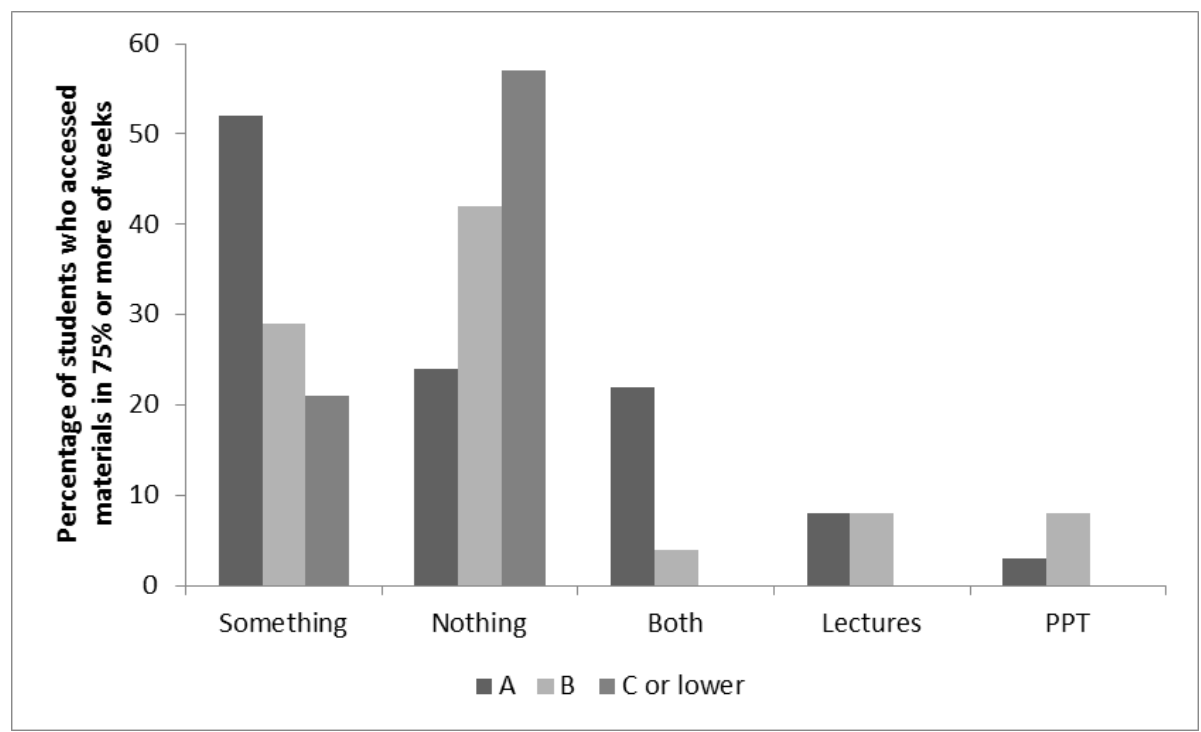

Figure 4. Percentage of students who did or did not access course materials in at least $75 \%$ of weeks.

In Figure 4, the percentage of students who did and did not access available materials in at least $75 \%$ of weeks is shown across grade categories. A cutoff of $75 \%$ was chosen to select students who made similar choices across the majority of opportunities to choose, rather than selecting students who were 
completely consistent in their choices, which may not be a reasonable expectation. Any student might have a week or two during the semester in which they simply didn't have time to access all materials, but they could still be considered to make consistent choices. Using a criterion of $75 \%$, we considered students to make consistent choices if they accessed materials in at least 9 of 12 weeks.

Of students who earned As, $52 \%$ accessed some form of materials in at least $75 \%$ of weeks (9-12 weeks), and $24 \%$ accessed no materials at all in $75 \%$ of weeks (9-12 weeks). The remaining $24 \%$ of students accessed materials between $25 \%$ and $75 \%$ of weeks (4-8 weeks). Of students who earned As, 22\% accessed both lectures and PPTs, $8 \%$ accessed lectures only, and 3\% accessed PPTs only in at least $75 \%$ of weeks. Of students who earned Bs, $29 \%$ accessed some form of materials in at least $75 \%$ of weeks (9-12 weeks), and $42 \%$ accessed no materials at all in $75 \%$ of weeks (9-12 weeks). The remaining $29 \%$ of students accessed materials between $25 \%$ and $75 \%$ of weeks (4-8 weeks). Of the students who earned Bs, $4 \%$ accessed both lectures and PPTs, $8 \%$ accessed only lectures, and $8 \%$ accessed only PPTs, in at least $75 \%$ of weeks. Of students who earned Cs or lower, $21 \%$ accessed some form of materials in at least $75 \%$ of weeks $9-12$ weeks), and $57 \%$ did not access any materials at all in at least $75 \%$ of weeks ( $9-12$ weeks). The remaining $22 \%$ of students accessed materials between $25 \%$ and $75 \%$ of weeks (4-8 weeks). None of the students who earned Cs accessed both lectures and PPTs, or only lectures or PPTs, in at least $75 \%$ of weeks.

\section{Discussion}

Online education presents students with unique opportunities to access material on their own schedule, multiple times, or not at all if they wish. The present study was an analysis of data gathered from an online graduate level course to assess student patterns of access to video lectures and PowerPoint slides, and to determine the relationship between these patterns and final grade in the class. These data show that students tended to view lectures and PPTs at gradually declining rates across the semester. Many students did not view either type of content after the first two weeks of class. This is similar to the finding by Hung and Zhang (2008) that online learners accessed course materials most in the first and last weeks of the semester.

The reason for the declining rates of lecture material access is not clear. While this type of analysis does not permit a strong inference to be made, there are several explanations that may account for this pattern. One possibility is that the demands of student workload gradually increased as the semester progressed, and students were forced to prioritize. In this case, it is not surprising that students would choose to complete required tasks that contributed directly to their grade before accessing supplemental material. It is also possible, however, that students did not find the lecture materials to be helpful or beneficial. This second possibility would seem to be less likely, as the lecture access decrease occurred gradually and did not stop entirely. Future research should include a measure of student feedback regarding the lectures to determine the causes for declining views and suggest further research directions.

When usage was analyzed across groups of students who earned different grades, it was found that a greater percentage of the students who earned As accessed some form of content in most of the weeks of the course, than students who earned Bs or Cs or lower. Conversely, a lower percentage of the students who earned As accessed no content in most weeks of the course, than students who earned Bs or Cs or lower. A greater percentage of students who earned As accessed both lectures and PPTs in most weeks than students who earned Bs. None of the students who earned Cs or lower accessed both or either type of content during most weeks of the course.

These findings are not surprising. It is to be expected that a greater proportion of students who earned As would have accessed the course materials consistently than students who earned lower grades. These outcomes support making video lectures and PPTs available to students and suggest that students who wish to earn As may be more likely to do so if they access these materials on a regular ba- 
sis. Additionally, these outcomes suggest that sticking with one strategy throughout the semester may be a way to improve the possibility of earning an $\mathrm{A}$ in an online class.

These results are also consistent with those obtained by Hung and Zhang (2008) in their analysis of online learning behavior and activity patterns. These researchers found that students with aboveaverage performance tended to access course materials substantially more frequently than those students who demonstrated below average performance. It is interesting to note, however, that some of the students in the present study who earned As did not access the lecture materials at all. The reasons behind this are not clear, although Hung and Zhang (2008) also described a similar finding. According to their analysis of data mined from online courses, the students who engaged in more active learning activities were more successful than those who made more use of passive learning activities, such as accessing readings and lectures. Hung and Zhang (2008) suggest that these students may simply be more effective learners. We must also consider the possibility that those who access passive learning activities may also be more likely to participate in the active learning activities that may be more important for their success in classes.

There are several limitations to the current study. Data were examined in a post hoc analysis, rather than through an experimental manipulation. The sample size is relatively small, and the distribution of grades in the course is strongly skewed. Most of the students in the course earned As, so comparisons across grading categories should be considered in that context.

Other concerns include that data were gathered via the reports feature of the Moodle online platform. The only data that we can analyze reflect how many times students clicked on the links for video lectures or PPTs. We cannot assume that they actually watched the lectures or read the PPTs after clicking on them. Students could easily click on both links and immediately close them, or open them and not attend to them. A learning management system might be able to provide information about how long videos or PPTs were kept open on a student's computer, but would still not be able to provide a solid measure of attention.

The current analysis looks at student choice and how it correlates with grades, not the true effectiveness of video lectures or PPTs. Course grades could be associated with other characteristics of students that are also correlated with choosing or not choosing to use these materials. In fact, given that the two types of content that were analyzed were directly related to a small proportion of the final grade, it should be assumed that actual access to the content is not the key factor in students' success. It might be more reasonable to assume that a student who regularly views lectures or PPTs possesses some characteristic that also leads him or her to put forth more effort in writing papers or studying. Perhaps some of the students who regularly accessed content were more conscientious about their work in general than students who did not. Another possibility is that some of the students who did not regularly access content might have had other demands on their time that made it difficult to devote enough attention to all schoolwork, such as full time jobs, or caring for young or disabled children. Therefore, the best conclusion that can be drawn from these data is that student behavior patterns of accessing online content may be related to final outcomes. We cannot, however, determine how effective the online content was in teaching the material to the students.

Future research might make use of single-subject experimental design to more closely evaluate the effectiveness of the materials. For example, an alternating-treatments design could be conducted by only providing lectures or PPTs or both on certain weeks. Instead of looking at course outcomes, the analysis could look at weekly quiz grades as a function of the availability and use of these materials.

Another direction for future research might be to analyze the elements of video lectures and PPTs to determine how to make them optimally effective for students in online programs. When a video lecture is determined to be helpful to a student, for example, what is it about the lecture that is helpful? How are PPTs best presented to students to facilitate learning and improve outcomes? 
Ultimately, the utility of this research rests in improving outcomes for individuals. An interesting and useful direction for future research might be to develop assessment tools that students can use when starting online education, to determine which strategies are most effective for them as individuals. This may help students to choose consistent strategies, rather than switching around. As noted in the data presented here, use of a consistent strategy was associated with an A grade, which is generally the outcome that a graduate student will seek in his or her coursework.

\section{References}

Batinic, B., Gruber, A., \& Jading, T. (2009). Learning with e-lectures: The meaning of learning strategies. Educational Technology \& Society, 12, 282.

Brecht, H. D., \& Ogilby, S. M. (2008). Enabling a comprehensive teaching strategy: Video lectures. Journal of Information Technology Education: Innovations in Practice, 7, 71-86. Retrieved from http://www.jite.org/documents/Vol7/JITEV7IIP071-086Brecht371.pdf

Chandrasekhar, A., Espiritu, B., Gruener, G., Hoyt, A., McNulty, J. A., \& Naheedy, R. (2009). An analysis of lecture video utilization in undergraduate medical education: Associations with performance in the courses. BMC Medical Education, 9, 6.

Cifuentes, O. E., \& Lents, N. H. (2009). Web-based learning enhancements: Video lectures through voice-over PowerPoint in a majors-level biology course. Journal of College Science Teaching, 39, 38.

Hines, R. A., \& Pearl, C. E. (2004). Increasing interaction in web-based instruction: Using synchronous chats and asynchronous discussions. Rural Special Education Quarterly, 23, 33-36.

Hung, J., \& Zhang, K. (2008). Revealing online learning behaviors and activity patterns and making predictions with data mining techniques in online teaching. MERLOT Journal of Online Learning and Teaching, 4, 426-437.

Latchman, H. A., \& Latchman, S. M. (2001). Lectures on demand in ALN: Enhancing the online learning experience. Journal of Asynchronous Learning Networks, 5, 85.

Marks, R. B., Sibley, S. D., \& Arbaugh, J. B. (2005). A structural equation model of predictors for effective online learning. Journal of Management Education, 29, 531-563.

Means, B., Toyama, Y., Murphy, R., Bakia, M., \& Jones, K. (2009). Evaluation of evidence-based practices in online learning: A meta-analysis and review of online learning studies. Washington, DC: Office of Planning, Evaluation, and Policy Development, U.S. Department of Education. Retrieved January 3, 2013 from http://www2.ed.gov/rschstat/eval/tech/evidence-based-practices/finalreport.pdf

Wang, F. (2008). Valuation of online continuing medical education and telemedicine in Taiwan. Educational Technology \& Society, 11, 190.

\section{Biographies}

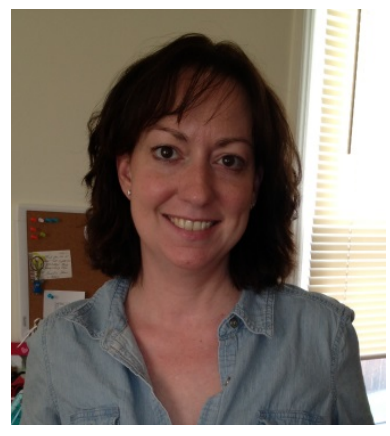

Dana Reinecke is a doctoral level Board-Certified Behavior Analyst (BCBA-D). She is an Assistant Professor and the Department Chair for the Center for Applied Behavior Analysis (CABA) at The Sage Colleges. Dana teaches and develops coursework within CABA, as well as advising students, training and supporting faculty and adjuncts, and managing the department. She developed and consults with the Achieve Degree at The Sage Colleges, a fully online Bachelor's Degree program for students diagnosed on the autism spectrum who find it difficult to attend college in a traditional setting. She was honored with The Sage Colleges' President's Award for Innovation for her work on this program. Dana also received the ELIJA Foundation's Chariot Award in honor of her work in the autism community on Long Island. She served a term as a Representative at Large (2010-2012) and is currently serving as Secretary (2012-2014) for the New York State Association for Behavior Analysis. 
Dana provides training and consultation to school districts, private schools, and families for children and adolescents with disabilities. She has provided consultation and training throughout New York, as well as in Mexico, Australia, and Northern Ireland. She has presented original research and workshops on the treatment of autism and applications of ABA at regional, national, and international conferences. She has published her research in peer-reviewed journals, written chapters in published books, and co-edited books on ABA and autism.

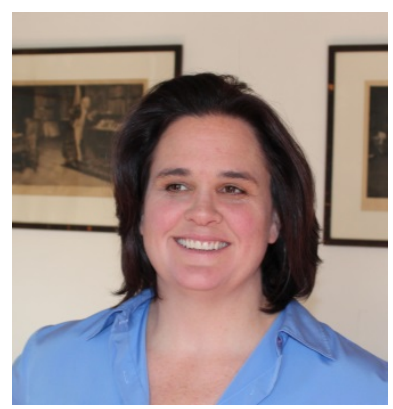

Lori L. Finn is an assistant professor at the Center for Applied Behavior Analysis at the Sage Colleges. She has extensive clinical experience providing services to individuals with autism, intellectual disabilities, and dual diagnosis. She is a doctoral level board-certified behavior analyst (BCBA-D) and earned her Ph.D. in Psychology in the Learning Processes/Behavior Analysis subprogram at the Graduate Center of the City University of New York. Her current research interests include staff training/management and online learning. 